\title{
Neuropsychological rehabilitation after closed head injury in young adults
}

\author{
GEORGE P PRIGATANO, DAVID J FORDYCE, HARRIET K ZEINER, \\ JAMES R ROUECHE, MARY PEPPING, BETH CASE WOOD
}

From the Presbyterian Hospital and the Neurosurgery Section, University of Oklahoma, Oklahoma City, USA

SUMMARY Cognitive and personality disturbances following severe closed head injury in young adults are associated with poor rehabilitation outcome. Yet systematic programmes for dealing with these disturbances have generally not appeared. The present report briefly describes the Neuropsychological Rehabilitation Program (NRP) at Presbyterian Hospital in Oklahoma City and the initial outcome data on eighteen closed head injury patients and seventeen untreated controls. Greater improvement in neuropsychological functioning occurred in the NRP patient group on selected variables, but generally the effects were modest. Emotional distress, however, substantially decreased in treated patients. Fifty percent of the NRP patients maintained productivity $75 \%$ of the time or more following rehabilitation, compared to $36 \%$ of the controls. Treatment successes showed less personality disturbances than treatment failures and better learning and memory scores post-treatment.

Young adults who suffer significant craniocerebral trauma (that is, length of coma at least 24 hours) frequently experience residual cognitive deficits. ${ }^{1}$ These deficits substantially interfere with the ability to be gainfully employed and return to reasonable psychosocial adjustment. ${ }^{2}$ While cognitive dysfunction may improve with the passage of time, ${ }^{3}$ the degree of eventual recovery is often not adequate to return to a previous lifestyle. It is not surprising, therefore, that these patients often show enhanced emotional and motivational disturbances over time. ${ }^{4}$ While some of these problems may reflect disturbed neurophysiology, ${ }^{5}$ others seem to be related to problems in coping with residual deficits. Clearly, both cognitive and personality disturbances, whatever the aetiology, are related to one another in traumatic head injury patients ${ }^{6}$ and are predictive of failure to return to work.?

While adequate outcome statistics are not available, present estimates suggest that only one-third

Address for reprint requests: George $\mathrm{P}$ Prigatano, $\mathrm{PhD}$, Department of Clinical Neuropsychology, Presbyterian Hospital, Northeast 13th Street at Lincoln Boulevard, Oklahoma City, OK 73104, USA.

Received 18 October 1983. Accepted 2 December 1983 of severe closed head injury patients may return to gainful employment using traditional rehabilitation methods. ${ }^{68} \mathrm{~A}$ large number of these unemployed patients "walk and talk" but experience difficulties in returning to work and establishing interpersonal relationships.

The question arises, therefore, can anything be done to substantially help these patients? There is growing enthusiasm that intensive forms of cognitive retraining and resocialisation skills retraining may help some of these patients. A few reports suggest that small group milieu based programmes, which emphasise intensive retraining, may have moderate success. ${ }^{910}$ These studies, however, have not used control groups nor reported to clinicians the characteristics of patients who most likely benefit from this type of treatment. Moreover, while modern rehabilitation programmes may emphasise cognitive retraining, many traumatic brain injury patients have emotional and motivational problems which are not systematically addressed. These personality difficulties often do not correlate highly with the estimated degree of brain tissue destroyed or severity of injury." This is not to say that some personality problems are unrelated to brain damage, but only that the relationship is a complex one. Recognition and treatment of these disturbances may be quite important for rehabilitation success. ${ }^{12}$ These obser- 
vations have suggested that intensive neuropsychological rehabilitation programmes might include both cognitive retraining and psychotherapeutic interventions, in order to maximise eventual psychosocial recovery.

In this report, initial outcome data on eighteen closed head injury patients, seen for such intensive neuropsychologically oriented rehabilitation, are presented. Seventeen closed head injury patients who underwent traditional rehabilitation, but for one reason or another, were unable to undergo intensive cognitive retraining and psychotherapeutic rehabilitation served as controls. Both sets of patients were referred to the senior authors for neuropsychological assessment and both sets were deemed to need intensive rehabilitation, above and beyond traditional means. Data were obtained regarding neuropsychological functioning, personality characteristics and social-psychological adjustment (particularly work status). In addition, the characteristics of those patients that were successful in returning to a productive lifestyle were compared to treatment failures.

\section{Methods}

\section{Subjects}

Patients seen in the Neuropsychological Rehabilitation Program (NRP) at Presbyterian Hospital, Oklahoma City, Oklahoma came from a larger population of outpatient referrals for neuropsychological evaluation following serious brain injury. Between February 1980 and August
1982 , twenty-eight patients accepted the recommendation for participation in the NRP and entered the programme. Of these twenty-eight patients, twenty-two had suffered significant traumatic head injury. Four of these twenty-two traumatic head injury patients dropped out of the programme before completion and were excluded from analysis in the present investigation. This left a core population of eighteen traumatic head injury patients who completed at least six months of work in the NRP. Three of these patients were seen for an additional six-month term in the NRP. Analyses of improvements in neuropsychological test data are based on only the first six-month programme for these subjects, however. The general characteristics of this population of eighteen head injury patients are shown in table 1 . Virtually all of them had cerebral contusions and/or brain stem contusion. As a group, patients were past the period of rapid spontaneous recovery, ${ }^{3}$ with a mean interval since injury of 21.6 months. Three had a post traumatic seizure disorder, twelve had residual paresis and six had residual signs of aphasia and/or dysarthria. All patients experienced substantial problems in post injury adjustment.

From the same neuropsychological referral population, from which the NRP patients originated, a group of similar traumatic head injury patients was selected to serve as controls. All neuropsychological test files for traumatic head injury patients seen between February 1980 and August 1982 , were retrospectively examined. The initial selection was a function of how closely each potential control patient matched the age, sex, education level, injury severity (as measured by the Russell-Neurenger Average Impairment Rating ${ }^{13}$ ) and time since injury characteristics of the NRP patients. From this group of subjects, seventeen controls were culled on the basis of having a subsequent follow-up neuropsychological examination at a time interval which

Table 1 Demographic data and neurological characteristics: NRP patients

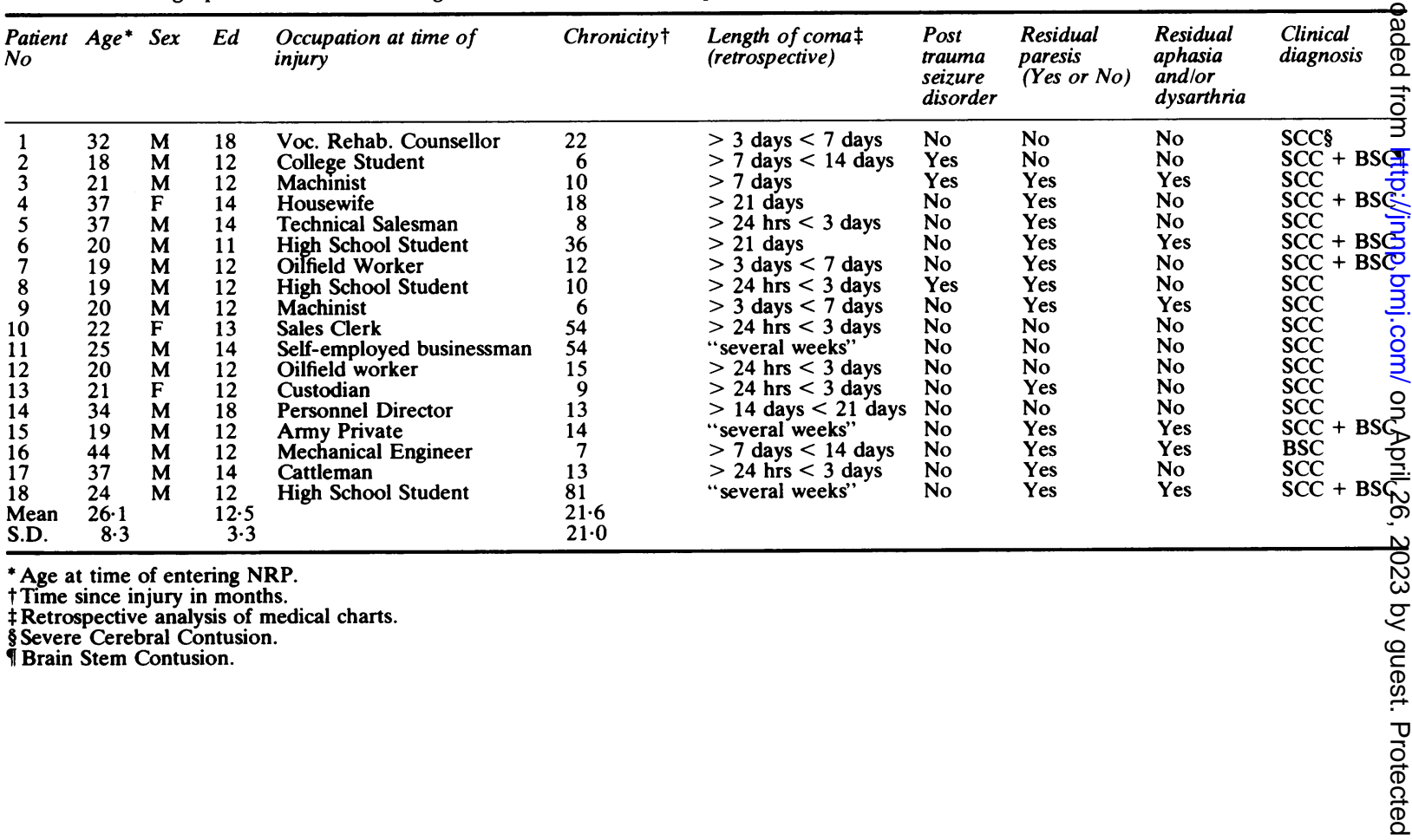


approximated the inter-test interval of the NRP patients. The variables of age, sex, education level, injury severity and chronicity have all been shown to influence either outcome following brain injury or neuropsychological test performance. ${ }^{2414}$ is 1617 While every attempt was made to select controls "blind" to their general outcome status, in some cases, this was impossible given the authors' familiarity with certain individuals. Recommendation to participate in the NRP programme was made to many of these seventeen controls following initial neuropsychological examination, but for a variety of reasons, these recommendations were not followed. In general, the controls were similar to the NRP patients in that they had suffered serious head injuries and were having difficulties adjusting to their residual deficits. Five had a post traumatic seizure disorder, five had residual paresis and six had residual signs of aphasia and/or dysarthria. Groups were relatively matched, therefore, on gross neurologic sequela (table 2).

\section{Neuropsychological rehabilitation program (NRP)}

A detailed description of the Neuropsychological Rehabilitation Program at Presbyterian Hospital, Oklahoma City, Oklahoma, is provided elsewhere. ${ }^{18}$ The general philosophy of treatment is that rehabilitation following brain injury must be intensive and coordinated, given the multitude of residual difficulties and the major problems in learning and remembering which accompany such injuries. Six to eight patients are seen in the NRP, four days per week, six hours per day, for approximately six months. Patients are treated both in small group and in individual treatment formats. Major themes of treatment include increased awareness and acceptance of the injury and residual deficits, intensive cognitive retraining of selected residual deficits and the development of a repertoire of compensatory skills designed to help each patient live effectively, in spite of intractable residual deficits. Also, the development of an understanding of their particular emotional and motivational disturbances and their personal reactions to the injury is vital in fostering independence and helping them seek a realistic vocational choice.

The treatment staff includes three clinical neuropsychologists, a speech and language pathologist, an occupational therapist and part-time physical therapists. A research psychologist helps develop various cognitive retraining materials and tasks. The staff works closely together to foster continuity and consistency among the various rehabilitation activities. In addition, relatives are met with on a weekly basis to provide support and help generalise what is learned in rehabilitation to the home environment. A consultant psychiatrist meets with the staff monthly to discuss the management of various patients.

\section{Neuropsychological test measures}

NRP patients received a comprehensive neuropsychological examination prior to their entering the programme. A repeat examination took place upon completion of six months of rehabilitation. Control subjects received the same basic battery of neuropsychological tests, although the assessments were not always as complete and inter-test interval was more variable than that of the NRP subjects. From the core neuropsychological test battery, the following measures were extracted for analysis in the present study:

(1) The Verbal IQ, Performance IQ, Vocabulary, Block Design and Digit Symbol subtests of the Wechsler Adult Intelligence Scale or WAIS-R. ${ }^{19} 20$

Table 2 Demographic data and neurological characteristics: controls

\begin{tabular}{|c|c|c|c|c|c|c|c|c|c|c|}
\hline $\begin{array}{l}\text { Patient } \\
\text { No }\end{array}$ & $A g e^{*}$ & Sex & $E d$ & $\begin{array}{l}\text { Occupation at time of } \\
\text { injury }\end{array}$ & Chronicity $\dagger$ & $\begin{array}{l}\text { Length of coma } \ddagger \\
\text { (retrospective) }\end{array}$ & $\begin{array}{l}\text { Post } \\
\text { trauma } \\
\text { seizure } \\
\text { disorder }\end{array}$ & $\begin{array}{l}\text { Residual } \\
\text { paresis } \\
(\text { Yes or No) }\end{array}$ & $\begin{array}{l}\text { Residual } \\
\text { aphasia } \\
\text { and/or } \\
\text { dysarthria }\end{array}$ & $\begin{array}{l}\text { Clinical } \\
\text { diagnosis }\end{array}$ \\
\hline $\begin{array}{l}1 \\
2 \\
3 \\
4 \\
5\end{array}$ & $\begin{array}{l}23 \\
26 \\
16 \\
22 \\
28\end{array}$ & $\begin{array}{l}\mathbf{M} \\
\mathbf{M} \\
\mathbf{F} \\
\mathbf{M} \\
\mathbf{M}\end{array}$ & $\begin{array}{l}14 \\
12 \\
11 \\
10 \\
16\end{array}$ & $\begin{array}{l}\text { College student } \\
\text { Construction worker } \\
\text { High School student } \\
\text { Navy recruit } \\
\text { Counsellor for juvenile } \\
\text { delinquents }\end{array}$ & $\begin{array}{r}7 \\
12 \\
12 \\
13 \\
9\end{array}$ & $\begin{array}{l}>24 \text { hrs }<3 \text { days } \\
\text { Unknown } \\
>3 \text { days }<7 \text { days } \\
>7 \text { days }<14 \text { days } \\
>7 \text { days }<14 \text { days }\end{array}$ & $\begin{array}{l}\text { Yes } \\
\text { No } \\
\text { No } \\
\text { Yes } \\
\text { No }\end{array}$ & $\begin{array}{l}\text { No } \\
\text { No } \\
\text { No } \\
\text { Yes } \\
\text { No }\end{array}$ & $\begin{array}{l}\text { Yes } \\
\text { No } \\
\text { No } \\
\text { Yes } \\
\text { mild } \\
\text { anomia }\end{array}$ & $\begin{array}{l}\text { SCC \$ } \\
\text { SCC } \\
\text { SCC } \\
\text { SCC } \\
\text { SCC }\end{array}$ \\
\hline 6 & 25 & $\mathbf{M}$ & 12 & $\begin{array}{l}\text { Salesman for oilfield } \\
\text { equipment }\end{array}$ & 8 & $>24 \mathrm{hrs}$ & No & $\begin{array}{l}\text { mild rt. } \\
\text { hand } \\
\text { weakness }\end{array}$ & No & SCC \\
\hline $\begin{array}{l}7 \\
8 \\
9 \\
10 \\
11 \\
12 \\
13 \\
14 \\
15 \\
16 \\
17 \\
\text { Mean } \\
\text { S.D. }\end{array}$ & $\begin{array}{l}36 \\
23 \\
24 \\
20 \\
15 \\
21 \\
22 \\
25 \\
23 \\
19 \\
26 \\
23.5 \\
5.1\end{array}$ & $\begin{array}{l}\mathbf{M} \\
\mathbf{M} \\
\mathbf{M} \\
\mathbf{M} \\
\mathbf{F} \\
\mathbf{M} \\
\mathbf{M} \\
\mathbf{M} \\
\mathbf{M} \\
\mathbf{M} \\
\mathbf{M}\end{array}$ & $\begin{array}{r}0 \\
11 \\
12 \\
14 \\
9 \\
11 \\
14 \\
12 \\
11 \\
12 \\
15 \\
11 \cdot 5 \\
3 \cdot 5\end{array}$ & $\begin{array}{l}\text { Oilfield worker } \\
\text { Plumber } \\
\text { Oilfield worker } \\
\text { College student } \\
\text { High School student } \\
\text { Army private } \\
\text { College student } \\
\text { Pipe fitter } \\
\text { Service man, oil company } \\
\text { High School student } \\
\text { Farmer }\end{array}$ & $\begin{array}{r}8 \\
12 \\
18 \\
5 \\
5 \\
8 \\
11 \\
8 \\
25 \\
20 \\
44 \\
15.9 \\
13.6\end{array}$ & $\begin{array}{l}>24 \text { hrs }<3 \text { days } \\
>7 \text { days }<14 \text { days } \\
>7 \text { days }<14 \text { days } \\
>24 \text { hrs } \\
>2 \text { wks } \\
\text { Unknown } \\
>2 \text { wks } \\
\text { Unknown } \\
>7 \text { days }<14 \text { days } \\
>7 \text { days }<14 \text { days } \\
>24 \text { hrs }<3 \text { days }\end{array}$ & $\begin{array}{l}\text { No } \\
\text { Yes } \\
\text { No } \\
\text { Yes } \\
\text { No } \\
\text { No } \\
\text { No } \\
\text { Yes } \\
\text { No } \\
\text { No } \\
\text { No }\end{array}$ & $\begin{array}{l}\text { No } \\
\text { Yes } \\
\text { No } \\
\text { No } \\
\text { No } \\
\text { Yes } \\
\text { Yes } \\
\text { No } \\
\text { No } \\
\text { Yes } \\
\text { No }\end{array}$ & $\begin{array}{l}\text { No } \\
\text { Yes } \\
\text { No } \\
\text { No } \\
\text { No } \\
\text { No } \\
\text { Yes } \\
\text { No } \\
\text { Yes } \\
\text { No } \\
\text { No }\end{array}$ & $\begin{array}{l}\text { SCC } \\
\text { SCC + BSCI } \\
\text { SCC + BSC } \\
\text { SCC } \\
\text { SCC } \\
\text { SCC } \\
\text { SCC + BSC } \\
\text { SCC } \\
\text { SCC + BSC } \\
\text { SCC } \\
\text { SCC + BSC }\end{array}$ \\
\hline
\end{tabular}

* Age at first examination.

† Time since injury in months.

$¥$ Retrospective analysis of medical charts.

\$Severe cerebral contusion.

Il Brain stem contusion. 
(2) The Memory Quotient, Logical Memory and Visual Reproduction subtests of the Wechsler Memory Scale. ${ }^{21}$ In addition, the number of difficult paired associates learned over the three trials of the Associate Learning subtest of the Wechsler Memory Scale was calculated. ${ }^{22}$

(3) The Trail Making Test, Finger Tapping Test and Tactual Performance Test of the Halstead Reitan Neuropsychological Test Battery. ${ }^{23}$

(4) Finally, the Russell-Neurenger Average Impairment Rating (AIR), based on the extended Halstead Reitan Battery, ${ }^{24}$ was calculated, when sufficient test data were present, to serve as a global index of overall neuropsychological status.

\section{Measures of personality functioning}

Assessment of personality characteristics of the NRP patients was undertaken with the KATZ Adjustment Scale Relatives Form. This standardised instrument provides a means by which significant others can rate the personality and social behaviour of their relatives. ${ }^{4}$ Scores were converted to age corrected $\mathrm{Z}$ scores on the basis of the normative population. ${ }^{25}$ Unfortunately, KATZ data was not available for all control patients.

\section{Follow-up interview}

NRP and control patients were contacted by telephone during the months of April and May, 1983. Each patient and, when possible, a relative was interviewed using a structured interview form developed by the NRP staff. Responses to questions concerning current work status and the work history, since the time of the last examination, were extracted for the present evaluation. If there were questions concerning the reliability of the patient's narrative, a vigorous attempt was made to obtain the same information from a relative.

\section{Statistical analysis of neuropsychological test data}

(A) NRP versus Controls While every attempt was made to match control subjects on what was felt to be important nontreatment variables affecting outcome from brain injury, it proved nearly impossible to do this adequately. As a result, post hoc statistical measures were undertaken to reduce the potential influence of confounding variables. This was accomplished through analysis of covariance, with the pool of covariates including age, educational level, time since injury of the first evaluation (chronicity) and time between the first and second evaluations (inter-test interval). To control for differences in initial level of impairment, pretest performance for each neuropyschological measure also served as a covariate. Analyses were completed only on the post-test scores, after adjusting for the various covariates. This procedure helped control for changes in test performance directly related to initial levels of impairment ${ }^{26}$ and allowed for generally greater statistical precision relative to the more traditional methods of analysing change scores. Statistical analyses of each neuropsychological variable were completed only for those subjects who had both pre- and post-test score values.

The general analysis of covariance procedure was as follows: first, a stepwise regression procedure ${ }^{27}$ was employed to isolate the covariates significantly related to each individual post test neuropsychological score. The grouping factor (NRP versus control) and initial pretest score values were "forced" into the regression model. After these sources of variance were entered, the remaining covariates (age, education, chronicity, inter-test interval) and their interactions were analysed to isolate which contributed additional independent variance to the regression model given the previously entered covariates. The covariate generating the largest $F$ statistic for variance added was entered into the model first. This process was repeated until the remaining covariates and their interactions could not generate a significant " $F$ statistic to enter the model" of 0.3 or less. Thus, for each neuropsychological post-test measure, a unique group of variables was identified, which covaried with the particular measure independent of the major grouping factor (NRP versus control). Secondly, analyses of covariance were subsequently completed on each neuropsychological test measure. As indicated, pretest scores were always employed as the first covariate in the model. Subsequently, the additional covariates and/or their interactions identified in the preceding stepwise regression analysis were also entered into the ANCOVA model. The complete model for each variable then yielded a comparison of post test neuropsychological scores between NRP and control patients adjusted for initial test performance and any other uncontrolled source of variance identified.

(B) Vocational successes and failures On the basis of the follow-up interview, the NRP patients were dichotomised into two groups based on their employment histories since discharge from the programme. The employed group consisted of those patients that remained productive for $75 \%$ or more of the time since discharge from the programme. The unemployed group were those patients who failed to maintain productive activities for $75 \%$ of the time following discharge. Neuropsychological test and personality measures were then reassessed on these two groups to determine whether these variables could discriminate the work outcome groups. Analyses of covariance were performed on post test scores for the neuropsychological and personality measures (after adjusting for pretest levels).

\section{Results}

\section{Matching variables}

With a few exceptions, the control patients were similar to the NRP patients on the matching variables. NRP patients were, on the average, $26 \cdot 1$ years old $(S D=8 \cdot 3)$ compared to $23 \cdot 5(S D=5 \cdot 1)$ for controls. The two groups were also similar with respect to the years of education attained. The NRP subjects averaging 12.5 years of school $(S D=3 \cdot 3)$ and the controls, $11 \cdot 5$ years $(S D=3 \cdot 5)$. The two groups were similar in sex composition with fifteen males and three females comprising the NRP subject population and fifteen males and two females comprising the control population. The slight differences between groups in age, education and sex composition were not statistically significant ( $p$ $>0.05)$.

There was a tendency for the NRP subjects to be 
more chronic than controls. At first testing, they averaged 21.6 months since injury $(S D=21)$, compared to 15.9 months $(S D=13.6)$ for controls. This difference fell short of statistical significance because of the sample size. The inter-test interval did reliably discriminate the two groups, however ( $F$ $=3.98, \mathrm{DF}=1 / 33, \mathrm{p}=0.05)$. NRP patients, on the average, had less time between testings $(7 \cdot 5$ months), compared to controls (12.6 months). The shorter initial chronicities and the longer inter-test intervals would tend to favour relatively greater spontaneous neuropsychological recovery among the controls relative to the NRP patients. ${ }^{2}$ In any event, these two variables were utilised as covariates in various statistical analyses, particularly for test scores for neuropsychological measures.

There was a trend for rehabilitation patients to be more neuropsychologically impaired than controls. The NRP patients obtained an initial mean Average Impairment Rating (AIR) of $2.35(\mathrm{~N}=17)$. For those control subjects for whom an AIR could be calculated $(\mathrm{N}=10)$, the AIR was somewhat lower $($ AIR $=1 \cdot 82)$. While this difference did not reach statistical significance, the initial level of impairment was deemed an important control variable and employed as a covariate in various analyses.

\section{NEUROPSYCHOLOGICAL TEST FINDINGS}

The NRP patients showed a trend for better neuropsychological functioning at post test compared to controls. These improvements were obtained after adjusting for the effects of initial level of performance and, where appropriate, age, education, chronicity and test interval. Tables 3 and 4 present mean values pre- and post-testing for the two groups.

The analyses of covariance indicated significantly better post-test performance for NRP subjects relative to controls for the following neuropsychological variables: WAIS Performance IQ $(\mathrm{F}=9.74, \mathrm{DF}=$

Table 3 Average Wechsler Test scores for NRP and control subjects

\begin{tabular}{|c|c|c|c|c|c|c|c|}
\hline \multirow{2}{*}{\multicolumn{2}{|c|}{ Test }} & \multicolumn{3}{|l|}{$N R P$} & \multicolumn{3}{|c|}{ Controls } \\
\hline & & $(N)$ & Pre & Post & $(N)$ & Pre & Post \\
\hline I & 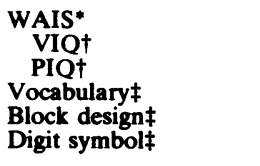 & $\begin{array}{l}(16) \\
(17) \\
15) \\
(18) \\
18)\end{array}$ & $\begin{array}{r}97 \cdot 2 \\
86 \cdot 8 \\
9 \cdot 0 \\
8 \cdot 9 \\
6 \cdot 3\end{array}$ & $\begin{array}{r}100.4 \\
95.5 \\
9.8 \\
10.9 \\
7.5\end{array}$ & $\begin{array}{l}(12) \\
(14) \\
(10) \\
15) \\
15)\end{array}$ & $\begin{array}{r}98 \cdot 3 \\
85 \cdot 8 \\
9 \cdot 6 \\
8 \cdot 0 \\
6 \cdot 3\end{array}$ & $\begin{array}{r}102 \cdot 3 \\
90.6 \\
9 \cdot 2 \\
9 \cdot 4 \\
6 \cdot 7\end{array}$ \\
\hline II & $\begin{array}{l}\text { WMS\& } \\
\text { WMQ } \\
\text { Logical memory } \\
\text { Visual reproduction } \\
\text { * of hard associates** }\end{array}$ & $\left.\begin{array}{l}(18) \\
(18) \\
18 \\
18\end{array}\right)$ & $\begin{array}{r}85 \cdot 4 \\
6 \cdot 9 \\
4 \cdot 3 \\
7 \cdot 6\end{array}$ & $\begin{array}{r}94 \cdot 9 \\
8 \cdot 0 \\
5 \cdot 6 \\
10 \cdot 1\end{array}$ & $\begin{array}{l}(13) \\
(13) \\
(13)\end{array}$ & $\begin{array}{r}90 \cdot 8 \\
7 \cdot 0 \\
6 \cdot 4 \\
7 \cdot 9\end{array}$ & $\begin{array}{r}92 \cdot 8 \\
6 \cdot 8 \\
6 \cdot 2 \\
9 \cdot 3\end{array}$ \\
\hline
\end{tabular}

* Both WAIS and WAIS-R employed.

†Prorated IQ values based on 5/6 verbal and 4/5 performance subtests.

$¥$ Scale scores.

8 Wechsler Memory Scale.

Raw scores.

**Total number of 4 hard associates learned over 3 trials.

Table 4 Average neuropsychological test scores for NRP and control subjects (selected Halstead-Reitan tests)

\begin{tabular}{|c|c|c|c|c|c|c|}
\hline \multirow[t]{2}{*}{ Test } & \multicolumn{3}{|l|}{$N R P$} & \multicolumn{3}{|c|}{ Controls } \\
\hline & $(N)$ & Pre & Post & $(N)$ & Pre & Post \\
\hline $\begin{array}{l}\text { AlR* } \\
\text { Tappingt }\end{array}$ & (17) & $2 \cdot 35$ & $2 \cdot 09$ & (9) & 1.98 & 1.77 \\
\hline $\begin{array}{l}\text { DH } \\
\text { NDH } \\
\text { TPTf }\end{array}$ & $\begin{array}{l}(16) \\
(16)\end{array}$ & $\begin{array}{l}42 \cdot 6 \\
39 \cdot 0\end{array}$ & $\begin{array}{l}44 \cdot 2 \\
42 \cdot 2\end{array}$ & $\begin{array}{l}(9) \\
(9)\end{array}$ & $\begin{array}{l}36 \cdot 2 \\
36 \cdot 8\end{array}$ & $\begin{array}{l}36 \cdot 8 \\
38 \cdot 3\end{array}$ \\
\hline $\begin{array}{l}\text { DH } \\
\text { NDH } \\
\text { Trail Making } \$\end{array}$ & $\begin{array}{l}(12) \\
(12)\end{array}$ & $\begin{array}{l}462 \cdot 4 \\
447 \cdot 9\end{array}$ & $\begin{array}{l}485 \cdot 1 \\
385 \cdot 9\end{array}$ & (6) & $\begin{array}{l}410.3 \\
386 \cdot 5\end{array}$ & $\begin{array}{l}403.5 \\
385 \cdot 7\end{array}$ \\
\hline $\begin{array}{l}\mathbf{A} \\
\mathbf{B}\end{array}$ & $\begin{array}{l}(18) \\
(17)\end{array}$ & $\begin{array}{r}60 \cdot 8 \\
163 \cdot 2\end{array}$ & $\begin{array}{r}45 \cdot 3 \\
133 \cdot 2\end{array}$ & $\begin{array}{l}(11) \\
\text { (11) }\end{array}$ & $\begin{array}{r}49 \cdot 3 \\
125 \cdot 8\end{array}$ & $\begin{array}{r}44 \cdot 3 \\
110 \cdot 4\end{array}$ \\
\hline
\end{tabular}


$1 / 21, p=0.005)$, WAIS Block Design Scale Score $(F=22 \cdot 81, D F=1 / 26, p=0 \cdot 0001)$ and Wechsler Memory Quotient $(F=5 \cdot 27, D F=1 / 27, p=0.03)$. In addition, there were nearly significant trends for NRP subjects to be less impaired at post test, compared to controls, on the Digit Symbol Subtest of the WAIS $(F=3.48, D F=1 / 25, p=0.07)$, the Tactual Performance Test time for the nondominant hand $(F$ $=4.73, \mathrm{DF}=1 / 9, \mathrm{p}=0.06$ ) and the Russell Neuringer Average Impairment Rating $(F=3 \cdot 85$, $D F=1 / 21, p=0.06)$. Only for the time to complete the Tactual Performance Test with the dominant hand did controls perform better than NRP subjects $(F=6.84, D F=1 / 9, p=0.03)$. None of the remaining analyses of covariance identified significant post-test performance differences between the two groups of subjects. The figure presents pre-post change scores on certain neuropsychological variables for NRP patients and controls.

\section{PERSONALITY TEST FINDINGS}

NRP patients showed more improvement in personality functioning compared to controls. Reports by their relatives indicated lower ratings (by at least one $\mathrm{Z}$ score) on helplessness, degree of social withdrawal, signs of general psychopathology and restlessness or hyperactivity. Mean age corrected Z-score values for both groups of patients are presented in table 5. NRP patients and controls were also compared as to whether or not they simply showed increases or decreases on each of the thirteen KATZ Adjustment Scales. The chi square analysis, using the Yates Correction, approached significance $\left(\chi^{2}=3.46, p=0 \cdot 06\right)$. NRP patients showed decline on twelve of the thirteen dimensions and increases in only one dimension. In contrast, controls showed decline on eight dimensions and increases on five dimensions.

WORK STATUS DURING FOLLOW-UP

NRP patients and controls were compared on

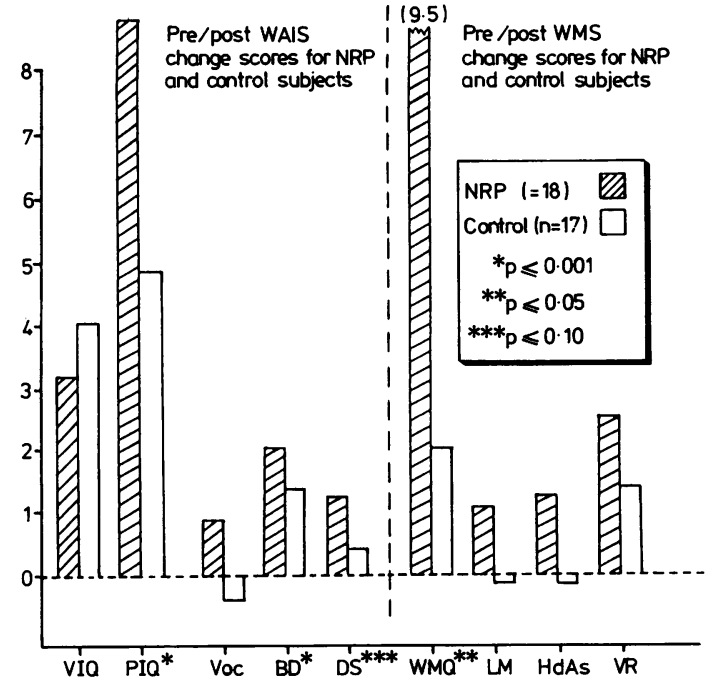

Fig Pre/post change Scores on the Intelligence and Memory tests.

whether or not they were gainfully employed (parttime or full-time) or actively engaged in a realistic school programme at the time of follow-up. Nine of the eighteen NRP patients $(50 \%)$ were classified as productive on this basis. Nine were not. Five of the controls $(36 \%)$ were productive at follow-up, eight were not. Three were lost to follow-up.

NRP PATIENTS: VOCATIONAL SUCCESSES VERSUS FAILURES

The neuropsychological and personality characteristics of the nine NRP patients who were working at the time of follow-up were contrasted to those NRP patients who had failed to do so. There were no significant differences in educational level, age or chronicity for the patients who were employed during follow-up versus those who were not. Similarly, while there was a trend on some measures for the

Table 5 KATZ adjustment Scale Z-scores (relative ratings of psychosocial adjustment) NRP versus Control Subjects

\begin{tabular}{|c|c|c|c|c|c|c|}
\hline & \multicolumn{3}{|c|}{$N R P(n=13)$} & \multicolumn{3}{|c|}{ Controls $(n=6)$} \\
\hline & Pre & Post & Chg. & Pre & Post & Chg. \\
\hline $\begin{array}{l}\text { Belligerence } \\
\text { Verbal expansiveness } \\
\text { Negativism } \\
\text { Helplessness } \\
\text { Suspiciousness } \\
\text { Anxiety } \\
\text { Withdrawal/retardation } \\
\text { General psychopathology } \\
\text { Nervousness } \\
\text { Confusion } \\
\text { Bizarreness } \\
\text { Hyperactivity } \\
\text { Stability }\end{array}$ & $\begin{array}{r}1.44 \\
1.15 \\
2.18 \\
2.42 \\
1.91 \\
0.67 \\
3.67 \\
5.87 \\
2.15 \\
2.02 \\
0.47 \\
1.94 \\
-3.89\end{array}$ & $\begin{array}{r}0.58 \\
0.99 \\
1 \cdot 20 \\
1 \cdot 13 \\
2 \cdot 66 \\
0.54 \\
2 \cdot 13 \\
4 \cdot 38 \\
0.94 \\
1.03 \\
0 \cdot 01 \\
0.79 \\
-2 \cdot 98\end{array}$ & $\begin{array}{l}-0.86 \\
-0.16 \\
-0.98 \\
-1.29 \\
+0.75 \\
-0.13 \\
-1.54 \\
-1.49 \\
-1.21 \\
-0.99 \\
-0.48 \\
-1.15 \\
-0.91\end{array}$ & \begin{tabular}{r|}
$2 \cdot 86$ \\
$3 \cdot 01$ \\
$2 \cdot 96$ \\
3.43 \\
$2 \cdot 47$ \\
$1 \cdot 25$ \\
$3 \cdot 17$ \\
$8 \cdot 14$ \\
$0 \cdot 36$ \\
$4 \cdot 86$ \\
$1 \cdot 46$ \\
$3 \cdot 58$ \\
-4.06
\end{tabular} & $\begin{array}{l}2 \cdot 26 \\
3.04 \\
3.31 \\
2 \cdot 47 \\
2 \cdot 67 \\
0.24 \\
3 \cdot 26 \\
6.41 \\
1 \cdot 31 \\
1.04 \\
1 \cdot 29 \\
2.29 \\
-3.89\end{array}$ & $\begin{array}{l}-0.40 \\
+0.03 \\
+0.35 \\
-0.96 \\
+0.20 \\
-1.01 \\
+0.09 \\
+1.73 \\
+0.95 \\
-3.82 \\
-0.17 \\
-1.29 \\
-0.17\end{array}$ \\
\hline
\end{tabular}


unemployed group to be more impaired in neuropsychological functioning, there were no statistically significant differences between the two groups on any of the neuropsychological measures. In contrast, relatives' ratings of emotional and motivational functioning, on the KATZ Adjustment Scale, did discriminate the two outcome groups. There was a tendency for the unemployed group to be rated as more deviant at pretest on most of the clinical dimensions of the KATZ-R. Only for the stability measure, however, was the difference statistically significant $(F=5 \cdot 17, D F=1 / 16, p=0 \cdot 04)$. At post-test, however, there were much greater differences. The unemployed group were rated as more deviant on most of the clinical dimensions compared to the employed group. Statistically significant differences were obtained for the verbal expansiveness measure $(F=4.93, D F=1 / 11, p=0.05)$, the negativism measure $(F=5.67, D F=1 / 11, p=$ $0.04)$, the general psychopathology measure $(F=$ $15 \cdot 19, \mathrm{DF}=1 / 11, \mathrm{p}=0.0003)$, the hyperactivity measure $(F=31.64, D F=1 / 11, p=0.0002)$ and the stability measure $(F=47 \cdot 41, D F=1 / 11, p=$ 0.0001).

Analyses of covariance completed on post-test scores after adjusting for initial test levels revealed some interesting differences between groups. Employed patients showed greater improvement on most of the neuropsychological tests. Significant differences between the two groups, however, were obtained only for the Digit Symbol subtest of the WAIS $(F=10.39, D F=1 / 15, p=0.006)$, the Wechsler Memory Quotient $(F=6 \cdot 04, D F=1 / 15$, $p=0.03$ ), the Visual Reproduction subtest of the Wechsler Memory Scale ( $F=4 \cdot 56, D F=1 / 15, p=$ $0.05)$ and the number of difficult paired associates learned from the Associate Learning subtest $(F=$ $7.73, \mathrm{DF}=1 / 15, \mathrm{p}=0.01)$. For the KATZ Adjustment Scale measures, following adjustment for initial values, the employed NRP patients tended to show greater improvement on the general psychopathology scale $(F=16 \cdot 44, D F=1 / 10, p=$ $0.002)$, the hyperactivity scale $(F=29 \cdot 16, D F=$ $1 / 10, p=0.0003)$ and the stability scale $(F=40.51$, $\mathrm{DF}=1 / 10, \mathrm{p}=0.0001)$ compared to the unemployed NRP patients.

\section{Discussion}

These preliminary findings on the effectiveness of an intensive NRP for chronic and moderately to severely impaired closed head injury patients suggests that such training may improve neuropsychological status and reduce emotional distress. Obviously, these findings need to be replicated in other settings, as well as obtained in a larger sample of patients. The data are encouraging because they document modest, but statistically reliable improvements on standardised neuropsychological tests. Past the period of so-called "spontaneous recovery", cognitive retraining activities appear to help patients improve their speed of information processing (as reflected particularly by the Performance IQ score). Improved neuropsychological status was also related to eventual gainful employment. The data further suggests that memory skills are very important in this regard. Clinically, it appears that NRP patients are more organised, less confused and this perhaps leads to better test performance. It will be important to longitudinally assess whether these improvements continue to maintain themselves or if periodic retraining activities are needed to sustain them.

These data and clinical observations also suggest that substantial improvement in interpersonal skills and reduction of emotional distress is possible with this type of intervention. Patients can be helped to be less helpless, socially withdrawn and hyperactive. They also can be taught to be more reliable and less anxious and depressed. These improvements appear to be related to reducing cognitive confusion and teaching patients to compensate for neuropsychological impairments. Teaching patients to recognise their own form of the catastrophic reaction $^{12}$ appears to be very important in enhancing their social adaptation. Without such therapeutic intervention, emotional disturbances do not get better on their own. ${ }^{4}$ It appears, therefore, that one of the most important benefits of intensive NRP is to improve psychosocial adjustment.

Both the neuropsychological and personality findings reaffirm what has been previously reported. Closed head injury patients who can learn information with practice, demonstrate reduced memory deficits and personality difficulties, generally have a better work adjustment. ${ }^{367}$ It is especially interesting, from a neuropsychological testing point of view, that improvement on the Wechsler Digit Symbol subtest score is a powerful discriminator between those closed head injury patients who return to work and those who do not. This test measures, among other things, the ability to learn with practice and speed of new learning. It does not sample higher abstract reasoning or problem solving skills. If the patient is within the lower limits of normal on this test by the end of rehabilitation, it suggests that he/ she has the basic cognitive capacities to be taught work skills and to be competitive, in terms of efficiency of functioning (at least for some jobs). This data would seem to parallel other research relating Performance IQ to vocational adjustment. ${ }^{28}$

While the above findings are encouraging, out- 
come on sustained employment are sobering. Initially, it was our impression that between $60 \%$ and $65 \%$ of the patients would work or were working shortly after their neuropsychological rehabilitation programme ended. With the passage of time, however, that percentage dropped to $50 \%$. Moreover, $36 \%$ of the controls return to gainful employment without intensive rehabilitation. This figure is compatible with other reports of between $33 \%$ and $40 \%$ gainful employment with traditional rehabilitative care. Why is there only a $14 \%$ difference in treated versus nontreated patients, in terms of work status, and can this figure be improved?

The methods used in our closed head injury programme were primarily designed to enhance neuropsychological function (particularly speed of information processing) and personality adjustment. To some degree, these goals were accomplished. It was hoped, however, that this would automatically lead to greater work productivity. We now see this as a somewhat naive assumption. Improving neuropsychological status and personality skills are necessary but not sufficient conditions for accomplishing a productive lifestyle. Specific training in this area is needed if the desired goal is to get the patient back to work and keep him/her gainfully employed. The NRP is presently being redesigned to include job placement and teaching of job maintenance skills. With this addition, we are hoping eventually to achieve a greater percentage of sustained independent living and productivity in our patients.

Patients who seem to have benefited most from this type of programme generally have the following test characteristics. The Average Impairment Rating is usually no greater than 2 to 2.25 at the onset of the rehabilitation programme. This is usually about twelve to eighteen months after traumatic head injury. Digit Symbol subtest score is usually at least six at the beginning of the rehabilitation programme and increases to eight or greater by the end of the programme. Rote verbal learning, as measured by the Associate Learning subtest of the Weschler Memory Scale approaches normal limits. Performance IQ typically is at least in the $80^{\prime}$ 's.

From the perspective of personality functioning, employable patients typically have affective disturbance which represent problems in coping (that is, the catastrophic reaction). Their problems with anxiety, anger, depression, etc, are in response to not knowing how to handle the cognitive, perceptual and motor limitations imposed by their brain injury. Pre-existing significant characterological and/or personality disturbances, foster a poor treatment outcome.

A good work history, prior to the traumatic head injury, and a supportive social milieu outside the programme which encourages the patient to take realistic steps in returning to work, are also vital. In this regard, it is not necessary that the patient have a great deal of formal education. It is more important that the patient had a stable work history. Patients who have a sporadic work history usually have poor treatment outcome.

Finally, the patients who seem to have neurologically based problems in awareness and who can be helped to realistically become aware and acceptant of residual neuropsychological deficits make the best candidates for this type of programme. Typically, these individuals show a willingness to use compensatory methods to get around deficits which impact their home and work life. The problems of awareness and acceptance are crucial concerns which need constant rehabilitative attention.

Some patients, who initially appeared to be ideal candidates for this type of programme failed; while others, who looked as if they were going to be poor candidates, succeeded. Clearly, the defining characteristics of those patients that would benefit from this type of neuropsychological rehabilitation programme are only broadly known. A successful outcome appears to be a result of a combination of factors, including the type and severity of brain injury, the premorbid characteristics of the patients, the skill and dedication of therapists and the local social and economic conditions which determine whether or not gainful employment is a practical goal. We are encouraged with these initial findings, in so far as they suggest that improvement can take place past the period of spontaneous recovery for many brain injured patients. Also, with the necessary training, the rate of gainful employment may be substantially better than what has been previously thought.

\section{References}

' Levin HS, Grossman RG, Rose JE, Teasdale G. Longterm neuropsychological outcome of closed head injury. $J$ Neurosurg 1979;50:412-22.

${ }^{2}$ Bond MR, Brooks DN. Understanding the process of recovery as a basis for the investigation of rehabilitation for the brain injured. Scand J Rehab Med 1976;8: 127-33.

${ }^{3}$ Bond MR. Assessment of the psychosocial outcome after severe head injury. In Outcome of Severe Damage to the Central Nervous System, CIBA Foundation Symposium 34, Elsevier, NY, 1975.

${ }^{4}$ Fordyce DJ, Roueche JR, Prigatano GP. Enhanced emotional reactions in chronic head trauma patients. $J$ Neurol Neurosurg Psychiatry 1983;46:620-4.

5 Prigatano GP, Stahl ML, Orr WC, Zeiner HK. Sleep and dreaming disturbances in closed head injury patients. J Neurol Neurosurg Psychiatry 1982;45:78-80. 
- Weddell R, Oddy M, Jenkins D. Social adjustment after rehabilitation: a two-year follow-up of patients with severe head injury. Psychol Med 1980;10:257-63.

' Bruckner FE, Randle APH. Return to work after severe head injuries. Rheumatol Phys Med 1972;11:344-8.

${ }^{8}$ Gilchrist M, Wilkinson $M$. Some factors determining prognosis in young people with severe head injuries. Arch Neurol 1979;36:355-8.

${ }^{9}$ Rosenbaum M, Lipsitz N, Abraham J, Majenson T. A description of an intensive treatment project for the rehabilitation of severely brain injured patients. Scand J Rehab Med 1978;10:1-6.

${ }^{10}$ Ben-Yishay Y ed. Working approaches to remediation of cognitive deficits in brain damaged persons. Rehabilitation Monograph \#64, NYU, 1982.

$"$ Lishman WA. Brain damage in relation to psychiatric disability after head injury. Br J Psychiatry 1968; 114:373-410.

12 Prigatano GP. Personality and psychosocial consequences after brain injury. In: Meir M, Dillard L, Benton A, eds. Neuropsychological Rehabilitation. London: Churchill Livingston. In press.

${ }^{13}$ Prigatano GP, Parsons OA, Levin DC, Wright E, Hawryluk G. Neuropsychological test performance in mildly hypoxemic patients with chronic obstructive pulmonary disease. $J$ Consulting Clin Psychol 1983;51:108-16.

${ }^{14}$ Braakman R, Gelpke GJ, Habbema JDF, Maas AIP, Minderhoud JM. Systematic selection of features in patients with severe head injury. Neurosurgery 1980;6:362-70.

15 Jennett B, Teasdale G, Galbraith S et al. Severe head injuries in three countries. $J$ Neurol Neurosurg Psychiatry 1977;40:291-8.

${ }^{16}$ Lewin W, Marshall TF, Roberts AH. Long-term outcome after severe head injury. Papers and Originals. Br Med J 1979;2:1533-8.
${ }^{17}$ Parsons OA, Prigatano GP. Methodological considerations in clinical neuropsychological research. J Consulting Clin Psychol 1978;46:608-19.

18 Prigatano GP, Fordyce DJ. Neuropsychological Rehabilitation Program, Presbyterian Hospital, Oklahoma City, Oklahoma. Caplan B, Bray G, eds. Handbook of Contemporary Rehabilitation Psychology, Springfield: Charles Thomas Publishing Company.

${ }^{19}$ Wechsler D. Manual-Wechsler Adult Intelligence Scale. New York: The Psychological Corporation, 1955.

${ }^{20}$ Wechsler D. Manual-Wechsler Adult Intelligence Scale (Revised Form).

${ }^{21}$ Wechsler D. Manual for the Wechsler Memory Scale, Form I. New York: The Psychological Corporation, 1945.

${ }^{22}$ Prigatano GP. The Wechsler Memory Scale: A selective review of the literature. J Clin Psychol 1978;34:(4),816-32, and as Archives of the Behavioral Sciences, Monograph \#54, October, 1978.

${ }^{23}$ Reitan R, Davison L. Clinical Neuropsychology: Current status and Applications. New York: John Wiley and Sons, 1974.

${ }^{24}$ Russell EW, Neuringer C, Goldstein G. Assessment of Brain Damage: A Neuropsychological Key Approach. New York: Wiley-Inter-science, 1970.

${ }^{25}$ Hogarty GE, Katz MM. Norms of adjustment and social behavior. Arch Gen Psychiatry 1971;25:470-80.

${ }^{26}$ Green PE. Analysing Multivariate Data. Hinsdale, Il.: The Dryden Press, 1978.

${ }^{27}$ Barr AJ, Goodnight JH, Sall P, Helwig JT, eds. A User's Guide to $S A S$ 76. SAS Institute, Inc., Raleigh, NC, 1976.

${ }^{28}$ Heaton RK, Pendleton MT. Use of neuropsychological tests to predict adult patient's everyday functioning. $J$ Consulting Clin Psychol 1981;49:807-21. 